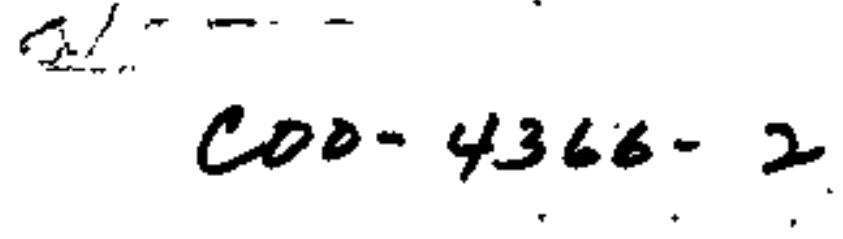

MOLECULAR MECHANISMS OF MUTAGENESIS AND CARCINOGENESIS

Final Report

for Period November 1, 1978-October 31, 1979

\title{
Mark Ptashne
}

Harvard University

Cambridge, Massachusetts 02138

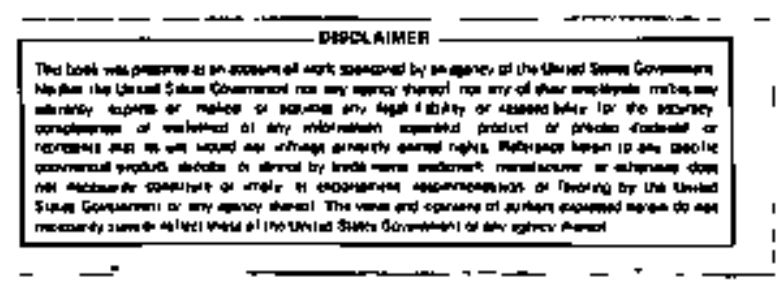

April 1980 


\section{DISCLAIMER}

This report was prepared as an account of work sponsored by an agency of the United States Government. Neither the United States Government nor any agency Thereot, nor any of their employees, makes any warranty, express or implied, or assumes any legal liability or responsibility for the accuracy, completeness, or usefulness of any information, apparatus, product, or process disclosed, or represents that its use would not infringe privately owned rights. Reference herein to any specific commercial product, process, or service by trade name, trademark, manufacturer, or otherwise does not necessarily constitute or imply its endorsement, recommendation, or favoring by the United States Government or any agency thereof. The views and opinions of authors expressed herein do not necessarlly state or reflect those of the United States Government or any agency thereof. 


\section{DISCLAIMER}

Portions of this document may be illegible in electronic image products. Images are produced from the best available original document. 


\section{ABSTRACT}

The recA gene product mediates induction of a battery of cellular functions in $E$. coli collectively known as the sos inducible functions. These include prophage induction, induction of filamentous cell growth, induction of DNA repair systems and induction of the recA gene itself. Prophage induction has been demonstrated to result from cleavage of the phage repressor protein by a specific protease function of the recA protein. Such cleavage destroys repressor function in lysogenic cells and allows the prophage to enter the vegetative growth cycle. Normally, the protease function of rect protein only becomes active in the cell in response to slgnals produced by agents (carcinogens) or treatments that specifically damage DNA or interfere with DNA replication. In the tif-l mutant of recA, however, the protease can be made to be active simply by raising the temperature of the culture from $30^{\circ}$ to $40^{\circ} \mathrm{C} ; \lambda$ prophage is induced ana the cell produces a normal burst of phage. Indeed, a11 known sos functions are also induced under these conditions. Thus, it has been proposed that all sos functions are similarly regulated by repressors that are sensitive to the recA protease function. We have sought to further characterize the recAmediated cleavage reaction and its requirements for $\lambda$ repressor in vitro and to extend our biochemical studies to a cellular sos repressor, the lexA gene product which is proposed to negatively regulate several sos inducible functions, including the recA gene, a gene controlling cell septation and the lexA gene itself. 


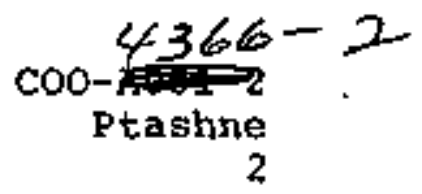

ISOLATION OF NEW $t i f$ MUTANTS

The activation of the recA protease function toward $\lambda$ repressor in vitpo has been the object of studies in several laboratories. Because recA protease function in the tif-l mutant is activated in vivo at $42^{\circ} \mathrm{C}$ in the absence of classical inducing treatments, we have shifted our emphasis in this area to attempts to understand the basis of such mutational activation. The goal has been to isolate new tif-like mutants in systems designed to provide opportunity for obtaining a variety of such mutants, especially with regard to strength and substrate specificity of the protease function. The general basis of the selections has been the spontaneous inactivation of $\mathrm{A}$ repressor in vivo. The study utilized the $\lambda$ precA specialized transducing phage in which the recA gene has been substituted for the nonessential $b$ region in the phage (see Figure 1). The reca gene on the phage is regulated by its natural promoter and not by any phage promoter. The concept behind the selection was that if lprecA bore a tif-like Irutation, then the phage should form plagues on a homoimmune lysogen since as it enters the cell, it should inactivate $\lambda$ repressor and develop normally. The system was devised using the tif-l derivative of lprecall which was found to exhibit the desired "virulent" phenotype only under a special set of conditions, namely, on a spr sfi recAA ( $\lambda \mathrm{KBl}$ ) host. The spr- mutation inactivates the $2 e x A$ gene product, the proposed repressor of the rooA gene, and permits constitutive reca gene expression from the phage soon after infection; the reaA deletion blocks synthesis of recA gene product from the host, thereby eliminating possible inhibitory co-dominant effects on the phageencoded recA product; the $6 \mathrm{fi}^{-}$(suppressor of filamentation) mutation permits survival of $s p p^{2}$ cells which would otherwise filament and die. The phage itself must bear a mutation in the al gene encoding phage repressor to prevent any contribution to repressor synthesis by the phage. A repressor is supplied by the $\lambda K B 1$ prophage (see Figure 2) in which the $a I$ gene of $\lambda$ is under the control of the lac promoter. This enables the level of $\lambda$ repressor in the lysogen to be experimentally regulated with IPTG (an inducer of the zac operon) independently of the elements normaliy controlling $\lambda$ repressor synthesis. The level of $\lambda$ repressor in such lysogens maximaliy stimulated with IPTG is about 40 of the monolysogen level (Backman and Ptashne, 1978). Under these conditions, $\lambda p^{2} e c A{ }_{c I}$ do not form plaques. However, within stocks of $\lambda$ precA ${ }^{+} I^{-}$(unmutagenized), plaque-forming mutant derivatives which resemble $\lambda$ ptif-1cI can be detected at a frequency of about $1-2 \times 10^{-6}$ (see Table).

Since $B$. coli mutants carrying certain other alleles of the texA gene (e.g., LexA3) produce a $t e x A$ product whose function cannot normaliy be inactivated by recA protease, the efficacy of the above system was initially uphefd by (a) failure of the mutant subpopulation within the AprecA phage stock to form plaques at any detectable frequency on the lexA3 version of the $\lambda \mathrm{KBl}$ lysogen and (b) by the failure to detect a virulent subpopulation 


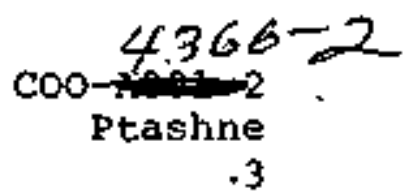

in the $\lambda \operatorname{te} x B 30 \mathrm{eI}^{-1}$ phage stock when plated either on the spr or the lex $A 3(\lambda \mathrm{KB})$ lysogen (see Table). Four additional genetic tests confirmed the presence of tif-like mutations in the virulent derivatives of $\lambda$ preca $\mathrm{eI}^{+}$:

(a) In a genetic backcross system, the immunity region bearing the $c I$ gene ( $i m m \lambda$ ) of each of 87 separate isolates was replaced first with the analogous immunity region from phage 21 (imm21) and then with the $i_{m m \lambda} \mathrm{I}^{-}$region from the parent. Each backcrossed isolate was demonstrated to have retained the ability to form plaques on the $\lambda \mathrm{KBl}$ lysogen. This confirms that virulence does not result from mutations in the immunity region, e.g., operator or oI transdominant mutants. The backcrossed derivatives of the $t i f-1$ and $r e c A^{+}$control phage strains retained their respective phenotypes.

(b) $\lambda p t i f-1 e I^{-}$fails to form plaques on the lexA $3(\lambda \mathrm{KBl}) 1 \mathrm{Y}-$ sogen (see Table) suggesting that the hyperactivity of the tif form of the reeA product is controlled on the phage as it normally is in the host chromosome. Each new tif mutant isolate (87/87) behaves similarly (but see below).

(c) $\lambda^{+}$and $\lambda$ precA ${ }^{+} \mathrm{I}^{+}$(imm $\lambda$, $i m m 21$, or $\left.i m m 434\right)$ form normal

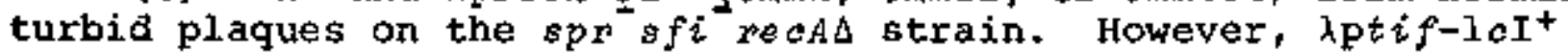
of each immunity type forms clear plaques on this strain as do the $a \mathrm{I}^{+}$derivatives of each of the 87 new mutant isolates. Clear plaque formation by the tif mutants presumably occurs through continuous tiff-mediated inactivation of repressor synthesized during phage development. The $e \mathrm{I} i$ a $\alpha^{-}$mutation of $i m m \lambda$ or imm434 block the clear plaque phenotypes of all the tif mutant isolates. Interestingly, only $10 \%$ of the new $\lambda$ ptif isolates form turbid plaques characteristic of $\lambda \mathrm{ptif}-1 \mathrm{eI} \mathrm{I}^{+}$plaque formation on the lexA 3 nonlysogen. The remainder which form clear plaques on the lexA3 host are considered to bear alterations which permit greater protease activity than $t i f-1$ or the other new isolates.

(d) The spr"sfit $t i f-1$ allele combination in the $E$. coli chromosome causes infecting $e I^{+}$phages $(i m m \lambda, i m m 21, i m m 434, i m m 22$, etc.) to form clear plaques; the aI ind derivatives form turbid plaques (Mount, 1977). This host phenotype can be mimicked in the $s \mathrm{pr}^{-} s \mathrm{fi}^{-}$recAd strain if made lysogenic with $\lambda \mathrm{ptif}-1$ (maintained by eIind on the prophage or by a plasmid which overproduces homoimmane repressor). Nine new tif mutant phages screened in this manner each reproduce the phenotype whereas the recA ${ }^{+}$parental phage does not.

No direct test has been performed to demonstrate that the mutations specifically lie within the reca gene. However, the similarity of their phenotypes to the $\lambda p t i f-1$ phage (sensitivity

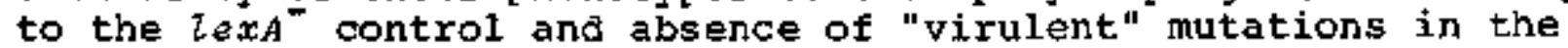
immunity region, together with their plating behavior) make it quite unlikely that the mutants comprise some unknown class of virulent phage types whose mutations are unrelated to recA gene 


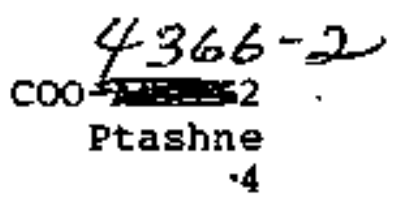

expression and which are also not observed in stocks of the $\lambda \in \mathrm{I}^{-}$or $\lambda \mathrm{p}$ Lex $30 \mathrm{c \textrm {I } ^ { - }}$ control phages.

In a second scheme, the spr- allele of the host has been substituted by the texA3 allele to reduce the level of reca gene expression from the phage. Neither $\lambda$ prect ${ }^{+} \mathrm{I}^{-}$nor $\lambda \mathrm{p} t i f-1 \mathrm{fl} \mathrm{I}^{-}$forms plaques on this host induced with IPTG (see-Table). However, if each phage is first grown on the mutb strain of $E$, coli (which increases the level of mutants in the phage stock by about $10^{4}$; see Degnen and Cox, 1974), plaque-forming derivatives of each phage were obtained (at irequencies of about $10^{-8}$ and $10^{-6}$, respectively, for reoA and tif-l forms of the phage). Analysis of eighteen such lsolates from the recAt parent reveals the presence of strong tif-like mitations. These mutants, interestingly, al1 retain specificity for $i n d^{+}$repressor. Judging from the frequency of occurrence and accounting for the 104-fold increase in the level of mutagenesis imposed by the mutD strain, the derivatives of the recA phage are almost certainiy double mutants. They could be of three types: (a) mutants bearing multiple tif-like mutations that together greatly enhance the protease activity of recA in the absence of high level recA gene expression from the phage, (b) mutants bearing a single tif mutation plus a separate mutation in the putative operator region (see below) to allow the elevated level of recA gene expression from the phage, or (c) mutants bearing single or multiple tif-like mutations which confer upon the protease the capacity to inactivate the $l e x A^{-}$product which should also lead to increased expression of recA from the phage. The mutants deriving from the tif-1 parent could also be of the above general types. The three types are being distinguished genetically.

The continuing study of the new tif-like mutants will attempt to further classify the isolates based on other genetic parameters such as temperature sensitivity, genetic map location, recombinational groups, dominance and activity toward $\lambda$ repressor and other sos repressors as well as toward their mutant forms. The subseguent biochemical study of the isolates will involve DNA sequence analysis of the mutants and analysis of the possible differences in protease activity of the mutant recA proteins and their requirements for such activity in the in vitro cleavage reaction. 
ISOLATION OF PECA OPERATOR-CONSTITUTIVE MUTANTS

Inactivation of the lexA product leads to constitutive high level expression of the recA gene. The lexa3 form of the lexA protein prevents normal inactivation of texA repressor function and therefore induction of sos functions following exposure to classical inducing agents. Such cells are extremely sensitive to agents that aamage DNA $(\mathrm{e} . \mathrm{g}$. , UV). We have attempted in a variety of systems to isolate recA mutants affected in regative control by the lexA 3 mutant protein hypothesizing that recA operator constitutive mutants should be one subclass of isolates obtained. The method that has provided mutants that exhibit "induced" phenotypes in the presence of the texA3 protein is the second selection scheme described for isolation of new tif-like mutants (see above). In addition to exhibiting substantial repressor inactivating capacity, the mutants, unlike their parents, confer enhanced UV resistance upon a lexa3 host (lysogenic for the noninducible $\lambda i n d^{-}$prophage to prevent vegetative growth of the isolates) suggesting that the elevated level of recA protein thought to be required for DNA repair can be exhibited by the mutants. Mutants identified genetically as bearing alterations in the site of texA binding (operator mutants) will be analyzed by DNA sequencing techniques and studied in a purified

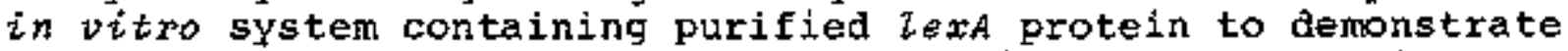
the effect of the mutations on the function of the putative recA operator.

FOOTNOTE

The texB30 allele of recA has been demonstrated to inactivate reca protease function or some function of the protein required for activation of the protease. 


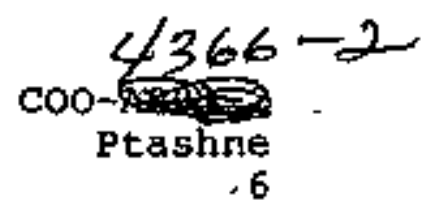

\section{TABLE}

Plating character of $\lambda$ precA and derivatives.

\begin{tabular}{|c|c|c|}
\hline Phage strains & $\begin{array}{r}\text { Effictency of } \\
\text { of } \\
\mathrm{spr}^{-}\end{array}$ & $\begin{array}{l}\text { Lysog } \\
\text { LexA3 }\end{array}$ \\
\hline$\lambda \mathrm{p} t i f-1 e \mathrm{I}^{-}$ & 1.0 & $<10^{-9}$ \\
\hline$\lambda$ precA ${ }^{+} \in \mathrm{I}^{-}$ & $1-2 \times 10^{-6}$ & $<10^{-9}$ \\
\hline$\lambda p t e x B 30 e I^{-}$ & $<10^{-9}$ & $<10^{-9}$ \\
\hline$\lambda \Leftrightarrow I^{-}$ & $<10^{-9}$ & $<10^{-9}$ \\
\hline$\lambda i m m 434 a \mathrm{I}^{-}$ & 1.0 & 1.0 \\
\hline
\end{tabular}




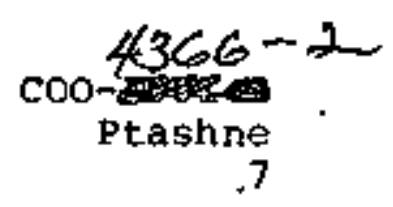

FIGURE 1

ApreaA (see HcEntee and Epstein, 1977).

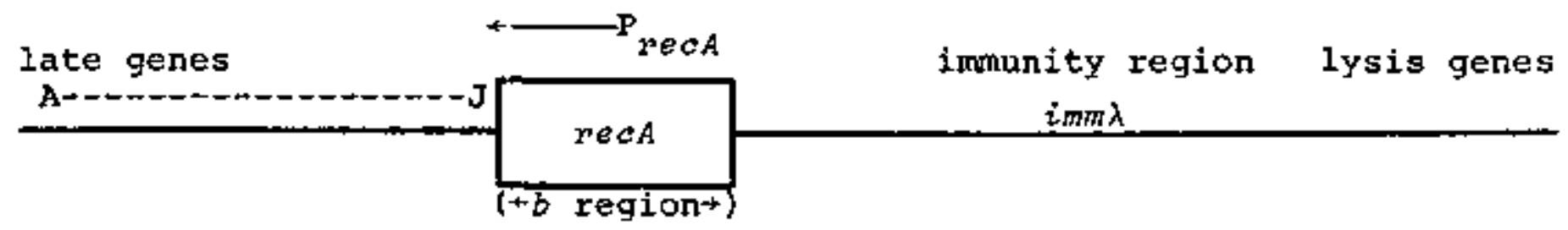




\section{FIGURE 2}

AKBl (see Backman and Ptashne, 1978).

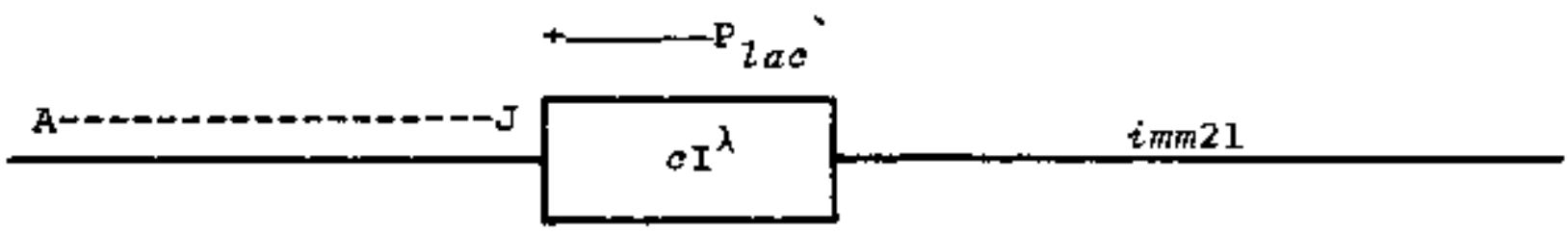




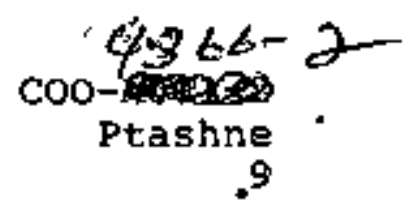

REFERENCES

Backman, K. and Ptashne, M. (1978) celt 13, 65-71.

Degnen, G.E. and Cox, E.C. (1974) J. Bact, 117, 477-487.

McEntee, K, and Epstein, w. (1977) Virol. 77, 306-318.

Hount, D.W. (1977) Proc. Natt. Acad. Sei. USA 74, 300-304. 